\title{
Research on the Taiwan Strait Cruise Circle
}

\section{CHEN Lingling, HUANG Jianshe, XIAO Hong XIAO Xiao}

\author{
(College of Navigation, Jimei University, Xiamen 361021, China)
}

\begin{abstract}
"The Taiwan Strait cruise circle" refers to cruise industry economic circle which located between Northeast and Southeast Asia cruise circle. It is regional economic concept. This paper through the present development situation of cruise economy and development background of Taiwan Strait cruise circle, separately from three aspects such as the cruise port facilities, tourist market, route setting to analyzed the prospect of "Strait cruise economic circle", do thinking and suggestions such as integration of resources surrounding ports, increase policy support, personnel training and other aspects to promote its progress.
\end{abstract}

Keywords: Taiwan Strait Cruise Circle; Cruise Industry; Regional Cruise Home Port

\section{Introduction}

Since twenty-first century, the North American market increasingly saturated and European international cruise market suffers the influence of economic crisis in past two years, cruise market gradually eastward. The Cruise company intends to open up new markets in China, they begin to pay attention to the tourist market of Asia and China, many of them choose China's coastal port as port of call, the number of International luxury cruise which received by China coastal port increased year by year. The development of cruise industry is of great significance to Xiamen economy, Xiamen has made the project at the "Twelfth Five Year
Plan" about improving port, developing passenger transport, transforming Dongdu area berths, expanding the cruise terminal shoreline and building the international cruise home port. There also have some development bottlenecks of Xiamen itself, such as passenger capacity, economic hinterland capacity as well as to the route policy about Taiwan and so on. So the research for "Taiwan Strait cruise circle" is particularly significant, how to break the bottleneck and create a good "Taiwan Strait cruise circle" is worthy of our study.

\section{Present situation of Cruise economy development}

Cruise industry is rapidly developing, although the impact of financial crisis in 2008 , the number of passenger growth has slowed, but then began to increase year by year. In 2012, Cruise passengers carried worldwide are about 15.7 million, and the worldwide cruise market value is estimated 24.5 billion. Cruise industry has an enormous contribution to the economy. Some cities of China have completed the constructions of International Passenger Center, such as Shanghai, Xiamen and Sanya. They also had opened a cruise home port route, Xiamen cruise home port normalization route has been carried out ${ }^{[1]}$. Cruise development condition in China gradual mature, outbound tourism market grows steadily, there is unlimited potential. This will bring opportunities and challenges to China's economy, and lay the foundation for the development of Chinese home port.

C 2013. The authors - Published by Atlantis Press

Foundation item: Soft science fund project of Fujian Province(2013R0077); Project of Xiamen Municipal Development and Reform Commission(20120016) 


\section{The development background of the "Taiwan Strait Cruise Circle"}

\subsection{The birth of the "Taiwan Strait Cruise Circle" idea}

In the case of Xiamen, the development of cruise economy is not only an opportunity, but also a challenge. The development of Xiamen cruise industry economy is undoubtedly promoted, but Xiamen also faced huge pressure of competition. Xiamen's economy hinter-land has a big gap with the Yangtze and the Pearl River Delta. Economic condition and regional population is far less than Shanghai and Tianjin. Xiamen should base on location advantage and the characteristics of their own, build the regional characteristics of the mother port city. Xiamen once only as a cruise port of call exists due to various factors. In December 2008, the realization of direct shipping links across the Taiwan Straits, the cross-strait passenger number revealed an increasing tendency, vigorous development of the cross-strait direct shipping created favorable conditions for cross-strait communication and personnel contact. Under background of promoting Straits economic zone and the Southeast international shipping center construction, Xiamen port and harbor in Taiwan jointly proposed the idea of "the cruise economic circle" that build 11 channel cruise line products with Xiamen as the center. (as showed in Table 1), highlights significant advantages of the Taiwan Strait cruise circle 8 hours "gold".

Tab1. The product of cruise line

\begin{tabular}{|c|c|}
\hline \multirow{3}{*}{$\begin{array}{l}\text { Three short range cruise } \\
\text { experience products }\end{array}$} & Xiamen-Jinmen-Penghu-Xiamen \\
\hline & Xiamen-Penghu-Keelung-Xiamen \\
\hline & Xiamen-Keelung-Taichung-Kaohsiung-Xiamen \\
\hline \multirow{3}{*}{$\begin{array}{l}\text { Three double port cruise } \\
\text { products }\end{array}$} & Shanghai-Xiamen-Taichung-Keelung-Shanghai \\
\hline & Shanghai-Xiamen-Penghu-Taichung-Keelung-Shanghai \\
\hline & Shanghai-Zhoushan-Taichung-Keelung-Shanghai \\
\hline \multirow{4}{*}{$\begin{array}{c}\text { Four three places of two } \\
\text { sides circular cruise } \\
\text { products }\end{array}$} & Xiamen-Penghu-Kaohsiung-hongkong-Xiamen \\
\hline & Hongkong-Xiamen-Keelung-Taichung-Kaohsiung-hongkong \\
\hline & Xiamen-Penghu-Kaohsiung-Guangzhou-Xiamen \\
\hline & Xiamen-Penghu-Kaohsiung-Shengzhen-Xiamen \\
\hline $\begin{array}{l}\text { One Taiwan around } \\
\text { Island Cruise products }\end{array}$ & Xiamen-Taichung-Kaohsiung-Hualie-Keelung-Xiamen \\
\hline
\end{tabular}

\subsection{The new concept of "Taiwan Strait Cruise Circle"}

Taiwan Strait cruise circle ${ }^{[2]}$ is regional economical concept, covered the ports including Xiamen, Shanghai, Zhoushan, Hongkong, Macao special administrative regions and Taiwan, Keelung, Taichung, Kaohsiung, Hualie and other ports, which laid between northeast Asia and southeast Asia cruise circle (as shown in fig. 1).

Xiamen has a unique advantage to Taiwan, which is beneficial to create "Strait cruise ring", radiation north to Northeast Asian countries and regions, and south to Southeast Asia countries and regions, built the dynamic regional cruise 
home port along the southeast coast of china finally.

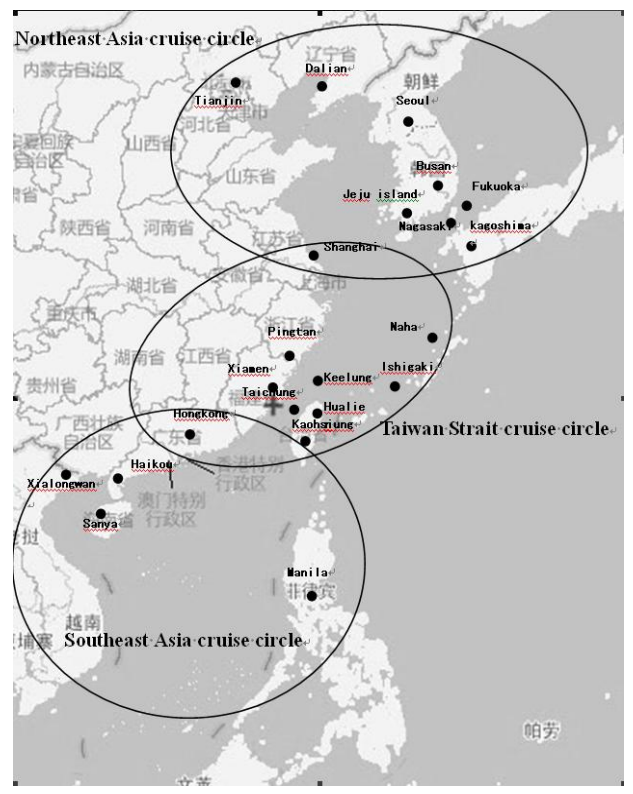

Fig. 1: Schematic diagram of Taiwan Strait cruise circle

\section{4. "Analysis of the development of Taiwan Strait Cruise Circle"}

\subsection{Cruise port facilities continue to improve}

From table 1, route setting involving Hongkong, Shenzhen, Xiamen, Shanghai, Guangzhou and Kaohsiung, Keelung, Penghu, Hualie, Taichung, Kinmen of Taiwan, which is mainly focussed on the Taiwan region. In order to promote cruise economy development, construct regional cruise circle, infrastructure construction of the home port is essential. With the rapid development of world and China cruise industry, cruise trend to giant, in 2011, Xiamen's government decided to transform Dongdu port area of Xiamen port, turn dongdu freight port to cruise home port. At present, the Wharf used to receive international cruise is located in the international cruise center. The birth of international cruise center has become a booster for Xiamen cruise economy, Dongdu port as a follow-up development of cruise center can berth 3 4 small and medium-size international cruise or above two 100000 ton cruise at the same time.

Keelung and Kaohsiung are Taiwan's two largest commercial ports, in order to fight for the cruise business opportunities, Keelung and Kaohsiung port present the construction of passenger transport and port building in 2009. The building can provide every 3000 passengers capacity, wharf can accommodate two 100000 ton cruises. In August 31, 2012, Keelung port received Asia's largest cruise ship "Ocean Voyager", in order to meet the "Voyager of the seas", Taiwan spent 300 million NT so as to the wharf can be deepened to 10 $\mathrm{m}$. We can say, Keelung and Kaohsiung port also have equipped the infrastructure conditions.

\subsection{The exploitation of tourist market}

Recent years, the number of mainland tourists in Taiwan region is increasing, before 2008 the increasing growth steady, and then showed a positively proportional growth (as shown in Fig. 2).

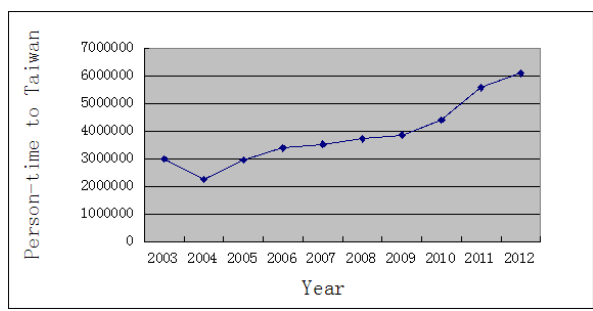

Fig. 2: Taiwan area inbound passengers change in recent 10 years ${ }^{[3]}$

This is because relevant travel policy on Taiwan is gradually relaxed from 2008, including direct cross-strait, "mini three links" and "three the direct links" mode, Mainland and Taiwan achieved the direct sea. In the second half of 2008, Taiwan 
began to open groups of people travel to Taiwan. 2011, Taiwan opened individual city freedom to the mainland, including Shanghai, Xiamen, Guangzhou, Shenzhen. etc. At the same time, opened Penghu, Kinmen, Matsu three the outlying islands free lines. There are about more than 7311000 entry people in Taiwan in 2012.

In "Channel cruise industry promotion meeting" which Held in July 30, 2013, the general manager of Hongkong Tourism Development Bureau Huang Zhuoxiong proposed: "Hongkong is a great tourist market". According the news of National Tourism Administration of Hong Kong and Macao: The number of Hongkong compatriots travel to the mainland up to 39770000 person-time in 1997, and in 2011 reach about 79360000 person-time, Hongkong compatriot entry number has doubled in 15 years, with an average growth rate of $5.06 \%$ annual, a total of 980 million people, accounting for $62.5 \%$ of the total number of mainland entry. In 2011, the two-way exchange number achieves about 108 million person time, as the world's largest two-way tourism customer market.

As one of the tourism developed port city of xiamen, has large local customers and extremely strong passenger appeal. Through 2012, received 41.2443 million tourists from home and abroad, which was an increase about $17.07 \%$. According to the data provided by the Xiamen international cruise center, since 2000, frequency of international cruise visiting increased year by year. During the period of "The 11th five-year plan", Xiamen received total of 82 international cruise ships and received international cruise visitors up to 146000 person-times.

Two-way tourism travel to Taiwan and Hong Kong tourists each year is so great If these customers can effectively attract, coupled with its own local customers in Xiamen, the customer market of "Taiwan Strait cruise circle" can get effective development, It is significant to boost both sides economy.

\subsection{The rationality of shipping routes setting}

Xiamen located in Taiwan Strait cruise circle center, north to Shanghai, south to Hongkong, closest to Taiwan, location advantages are obvious, and the route distance to Taiwan, Hong Kong and Shanghai port meet evening-morning plan, highlight "golden eight hours' advantage. It's a reasonable adopting the combination of short and medium line setting, it can adapt to Chinese living habit at the same time. Due to the constraint of holiday system in our country, if setting a longer route, some tourists may not be able to have so much time, or schedule will be disrupted.

Route setting also opened up a double home port routes, taking Shanghai port and Xiamen port as home port operation. It will be more advantageous extends the tourist market and increase flow rate, leading to regional tourism development, promote the cross-strait economic.

\section{Some thoughts and suggestions on promoting the "development of the Cruise Circle"}

\subsection{Integrate resources around the port, attract customers}

Tourist capacity limited is one of the main bottlenecks for Xiamen. In order to attract tourists, Xiamen could integrate resources around. Xiamen itself is an international competitive tourism city, the around tourist resources are also very rich There are Tulou, Mazu, Coastal Volcano National Geological Park and humanistic landscape in three hours traffic circle, cruise passengers can conveniently realize the travel. Secondly, developed transport system provides a reliable custom supply. In Air transport, Xiamen International Airport opened 170 routes access to 86 
city, airport passengers formally break through 2000000 person time in 2011. In Road traffic, Fuxia, Xiashen, Xiangpu railway created a further development condition of Yangtze River Delta, Pearl River Delta and inland tourist market ${ }^{[4]}$.

\subsection{Contact with the cruise company} and travel agency, to achieve normal operation of cruise home port

Xiamen is one of the earliest received ports for international cruise in Chinese mainland. It is the first Chinese mainland port on a regular international cruise line. But because Xiamen have not a system planning of cruise industry before, she unable to provide stable and sufficient custom sources and then unable to attract cruise to port to set up home port line, thus restricting the normal operation of its cruise. Now, "The Taiwan Strait cruise circle" laid a foundation for the Xiamen cruise home port development. Xiamen will actively engage with cruise company and travel agency, according to market prospects of "the Taiwan Strait cruise circle", attracting cruise to port to set up home port line, promoting travel agency cooperation operation, realize the normal operation of Xiamen cruise.

\subsection{Strengthen the exchanges and cooperation between the home port city}

Although Xiamen has the advantage of location and market bases in building "Taiwan Strait cruise circle", there are still a lot of obstacles. The local and foreign tourist market of Xiamen is very large, but there is still a big gap when compared with the Shanghai and Tianjin. Xiamen should actively share experiences with other cruise home port city, such as Shanghai, Tianjin and so on, strengthen the exchanges, summarizes the problems and avoid appearing similar mistakes in the construction.

At channel cruise industry promotion conference which holds in July 30, 2013, General Manager of International Cruise Port Development Limited of Shanghai Wusongkou Lu Guangyuan was asked, which obstacle has encountered in the development? He noted, the procedures of customs declaration and inspection is too much, and the passenger flow volume exceeded the construction prediction of passenger transportation center, little rest places lead to comfort level is not enough, so in the construction of the passenger terminal building, Xiamen should refer to the opinions of other big companies.

At the same time, China's international cruise port realizes multi linked ${ }^{[5]}$ policy in Xiamen, Xiamen should strengthen the cooperation with Shanghai and Tianjin port, put Xiamen into its existing south route of affiliated port to achieve the cruise ship anchored accumulation.

\subsection{Increase policy support}

Because of the special relationship with Taiwan, Xiamen lacks the characteristic ship route policy of Xiamen home port, Taiwan short experience product may be the most attractive cruise products in Xiamen. But the two sides now there is no direct flights right with Taiwan about cruise, at present can only use the charter form which should apply for the special case direct charter four months in advance. So, first of all, we have to apply for the shipping rights, promote the normal operation of cruise tourism products in policy.

On other hand, the soft environment in Xiamen now is weak, regarding tourism's characteristic routes of Taiwan, there is no convenient policy, registration time is long, the customs procedures and port management system are not perfect. If it can raise the speed of the registration and customs clearance, comfortable of service and tourist attraction will be effectively improved ${ }^{[6]}$. 


\subsection{Talent cultivation}

In China, the cruise industry has just emerged in recently years, construction of the cultivation of talents is also urgently when Xiamen accelerates the construction of the cruise terminal and other hardware facilities, if without professional serve for cruise market, perfect hardware facilities can't meet the needs of the market as well. Because of lacking cruise professional management personnel and consultant, hindered the promotion pace of cruise industry. Now, the cruise tourism mostly adopts charter form with team into and team out, though travel agencies to attract tourists. The cruise is a tourist destination nature. Travel agency should promote the cruise concept and cruise knowledge, rather than just the scenic landscape. In the face of cultivating professional talents of the cruise, there are two ways: one is social recruitment, from social workers who engaged in cruise industry, these people have a lot of experiences. This is the most efficient way. Another way is to open cruise curriculums in Colleges and universities to train the personnel talents. However, teachers, textbook selection and teaching base scarcity are also a question we must research first ${ }^{[7]}$.

\section{Conclusion}

The development of Xiamen cruise is in the initial stage, the construction of "the Taiwan Strait cruise circle " is still faced with great challenges. It requires all parties continuous efforts in the future development, including cruise company, port, the travel agency and government, strengthen multilateral cooperation. At the same time, government and enterprises should increase investment of scientific research, encourage relevant institutions actively participates in the research on the development of cruise industry. In this way, "the Taiwan Strait cruise circle" can obtain long-term, sustained development. I believe the development of "the strait economic cruise circle" will promote the construction of the Straits Economic Zone and the Southeast international shipping center, so as to drive the entire southeast tourism economical development, laid a solid foundation for Xiamen regional cruise home port.

\section{References}

[1] Yanzi Wu, yunhai Zhu. Sanya Cruise Economic Development opportunity and challenge[J]. China Ports, 2011(4):44-47.

[2] Heqiang Xing,Huiling Yang. Xiamen international cruise center_one body two wings _ casting brand[N]. Outside the China Times, 2013-03-13(008)

[3] Hangqu. Analysis of mainland tourist population status and influence of Taiwan area in China[D]. Jilin University, 201305

[4] Fen Qin, hi Wang. Some reflections and suggestions on speeding up the development of Xiamen cruise tourism[J]. China Ports, 2013 (05) : 11, 25-27.

[5] Minghua Wu. "Multi link" boosts the cruise industry development[J]. China Ocean Shipping, 2009 (12) : 16-17.

[6] Shiwei Chen, Hongbin Chen. Analysis of development strategy of Xiamen cruise economic $[\mathrm{J}]$. Science and Technology Information, 2007(11):485.

[7] Lu Wang. Study on current situation of Xiamen cruise tourism talents[J]. Journal of Hubei Institute of Technology, 2012(10):30-31. 